\title{
EP-33
}

\section{Short-term outcomes of anatomic right anterior liver sectionectomy for hepatocellular carcinoma with Glissonean pedicle approach}

\author{
The Anh PHAM*, Minh Hoang TA, Huy Phuong TRINH \\ Department of Hepatobiliary and Pancreatic Surgery, Vietnam National Cancer Hospital, Ha Noi, Vietnam
}

Introduction: Hepatocellular carcinoma (HCC) is a common malignant disease in Vietnam with a high mortality rate. Anatomic right anterior liver sectionectomy is the prior choice for HCC which locates in this area if we can't perform right or central liver resection. The extrafascial approach are recognized as the Glissonean pedicle approach. When the Glissonean pedicles are ligated, anatomical hepatectomy area reveals.

Methods: Forty-seven patients with diagnosis of HCC who underwent anatomic right liver anterior sectionectomy with Glissonean pedicle approach from March 2017 to March 2020 in our Department. Two techniques were used including extrafascial and extrafascial-transfissural approach (when the tumor locates near the right anterior glissonean pedicle).

Results: The mean age was $56.7 \pm 11.82$ year olds with male:female ratio is $10.75: 1$. Positive rates for hepatitis B is $74.5 \%$. Selective control of Glissonean pedicle was successful in all cases: 35 cases (74.47\%) with extrafasical approach and 12 cases (25.53\%) with extrafascial-transfissural approach. There are 40 cases (85.1\%) having intermittent clamping in a manner of 15 minutes of ischemia and 5 minutes of reperfusion repetitively and 7 cases (14.9\%) having continuous hemihepatic vascular inflow clamping. The mean amount of intraoperative blood loss was $200 \pm 120 \mathrm{~mL}$ and no transfusion. The mean operation time was $182.23 \pm 54.07$ minutes. The median postoperative hospital stay is $7.52 \pm 2.25$ days. No patients had necessity for blood transfusion. There was 1 case having liver failure and no mortality.

Conclusions: Anatomic right anterior liver sectionectomy for HCC with Glissonean pedicle approach is feasible, safe, and effective procedure. 